\title{
Informações sobre o uso de medicamentos no esporte
}

\author{
Marta Goldman Feder, Jari Nóbrega Cardoso, Marlice A. Sípoli Marques e Eduardo Henrique De Rose
}

\section{INTRODUÇÃO}

O aumento do uso de medicamentos destinados a melhorar o desempenho do atleta tem motivado uma ação intensa das autoridades esportivas nacionais e internacionais, visando preservar não apenas os aspectos éticos da competição mas, sobretudo, a saúde dos esportistas que dela participam.

$\mathrm{O}$ conceito de dopagem, anteriormente à proibição de certas classes de agentes farmacológicos, referia-se à administração ou uso pelo atleta de qualquer substância exógena com a intenção de influir na performance do mesmo durante a competição. A partir da listagem dos medicamentos não permitidos e restritos, a dopagem é caracterizada pela detecção de tais substâncias na urina do ou da atleta durante treinamento ou competição.

O progresso acelerado das Ciências do Esporte e o surgimento de novos métodos e sistemas destinados ao incremento da capacidade física faz com que seja necessária uma legislação dinâmica, moderna e suficientemente abrangente.

Em função disto, torna-se problemática a atualização constante dos profissionais que atuam em competições, aumentando desta forma o risco de um uso acidental de medicamentos restritos ou proibidos. Além disto, em virtude das dificuldades financeiras que frequientemente afligem o esporte, muitas vezes os atletas não dispõem de uma atenção médica especializada, quer para competições no Brasil, quer para suas viagens ao exterior.

O objetivo deste trabalho é oferecer a possibilidade de uma consulta rápida para saber se um determinado medicamento, da nossa farmacopéia ou produzido em outro país, pode ser usado durante uma competição esportiva, sem nenhum risco de sanções por uso de substâncias proibidas.

\section{LEGISLAÇÃO DO COMITÊ OLÍMPICO INTERNACIONAL - COI}

A Comissão Médica do COI foi criada em 1967, um ano antes dos Jogos Olímpicos da Cidade do México. A partir

\footnotetext{
Endereço para correspondência:

Dr. Eduardo Henrique De Rose

E-mail: ehderose@terra.com.br
}

destes Jogos, foi iniciado o controle sistemático de doping em Jogos Olímpicos de Inverno e de Verão.

De acordo com a Comissão Médica do COI, a lista de substâncias proibidas circulada em janeiro de 2000 contém cinco classes farmacológicas: estimulantes, narcótico-analgésicos, agentes anabolizantes, diuréticos e hormônios peptídicos. Ademais, inclui três métodos igualmente proibidos: a manipulação física, química e farmacológica de urina, a administração de transportadores artificiais de oxigênio e substitutos de plasma, e ainda transfusão de sangue.

Após fevereiro de 1993, o grupo de betabloqueadores, que era previamente proibido, foi transferido à categoria de droga restrita, cabendo às Federações Internacionais de cada modalidade esportiva incluir ou não esta substância no elenco das categorias proibidas. Os betabloqueadores são atualmente proibidos em esportes de precisão e pilotagem, tais como arco e flecha, tiro, pentatlo moderno, esgrima, saltos ornamentais, ginástica e equitação.

A lista de classes farmacológicas e métodos proibidos é atualizada a cada ano, no mês de janeiro, em função do que está sendo utilizado ou já não tem mais sentido de ser usado pelos atletas, e a partir de pesquisas realizadas e que permitem um maior conhecimento dos agentes dopantes.

Qualquer substância que pertença a classes farmacológicas proibidas não poderá ser usada, mesmo se não estiver listada como exemplo. O termo "compostos correlatos" utilizado no fim de cada classe farmacológica descreve drogas relacionadas esta categoria, seja pela sua estrutura química, seja por seu efeito farmacológico.

A lista que vigora este ano, e que será a usada para os Jogos Olímpicos de Sydney, é a seguinte:

\section{CLASSE DE SUBSTÂNCIAS DOPANTES PROIBIDAS}

\section{A. Estimulantes, tais como:}

Anfepramona, anfetaminil, amineptina, amifenazol, anfetamina, bambuterol, bromantano, benzofetamina, cafeína*, carfedon, catina**, cocaína, clorfentermina, clobenzorex, clorprenalina, cocaína, cropropamida, crotetamida, dimetanfetamina, efedrina**, etafedrina, etamivan, etilanfetamina, etilefrina, fencamfamina, fenetilina, fenfluramina, fenproporex, formoterol, furfenorex, heptaminol, me- 
tilenodioximetanfetamina (MDMA), mefenorex, mefentermina, mesocarb, metanfetamina, metoxifenamina, metilendioxianfetamina (MDA), metilefedrina**, metilfenidato, morazona, nicetamida, norfefluramina, parahidroxianfetamina, pemolina, pentetrazol, pentilentetrazol, fendimetrazina, fenmetrazina, fentermina, fenilefrina, fenilpropanolamina, pipradol, foledrina, prolintano, propilhexedrina, pseudo-efedrina, pirovalerona, reproterol, salbutamol***, salmeterol ${ }^{* * *}$, selegilina, estricnina, terbutalina*** e compostos correlatos.

Observe-se que algumas substâncias são positivas apenas quando encontradas acima de certas concentrações urinárias, para evitar problemas de ingestão alimentar ou contaminação por uso de medicações populares:

* cafeina será positiva sempre que se apresentar em uma concentração urinária superior a 12 microgramas $/ \mathrm{ml}$.

** catina será positiva sempre que se apresentar em uma concentração na urina superior a 5 microgramas $/ \mathrm{ml}$. Efedrina e metilefedrina deverão estar acima de 10 microgramas/ml. Fenilpropanolamina e pseudo-efedrina, em concentrações superiores a 25 microgramas $/ \mathrm{ml}$.

Tenha uma atenção especial para usar sem problemas medicações para asma:

$* * *$ = salbutamol, salmeterol e terbutaline poderão ser usados, mas apenas sob forma de aerossol e especificamente para prevenir e/ou tratar asma e asma induzida pelo exercício. A autoridade médica poderá, eventualmente, solicitar uma espirometria para caracterizar a presença desta patologia. Assim mesmo, se o salbutamol for encontrado na urina em concentração superior a 100 nanogramas $/ \mathrm{ml}$, o atleta poderá ser penalizado por dopagem por estimulante. Para consumo destas substâncias como anabolizante ver o item C.2 - beta-2-agonistas).

De qualquer forma, sempre que antiasmáticos forem utilizados, o médico responsável pela equipe, particularmente nos Jogos Olímpicos, deverá fazer uma notificação por escrito à autoridade médica relevante.

$\S$ NOTA: Preparações com imidazol são aceitáveis apenas para uso tópico; vasoconstritores como a adrenalina podem ser usados com agentes anestésicos locais. Preparações tópicas (ex.: nasal, retal e oftalmológica) de adrenalina e fenilefrina são permitidas.

\section{B. Narcótico-analgésicos, tais como:}

Alfaprodina, anileridina, buprenorfina, dextromoramida, diamorfina (heroína), dipipanona, etoheptazina, hidrocodona, levorfanol, metadona, morfina*, nalbufina, pentazocina, petidina, fenazocina, trimeperidina e compostos correlatos.

Para que a morfina seja positiva deverá estar presente na urina em concentração superior a 1 micrograma/ml, evi- tando falsos positivos por ingestão de pães decorados com sementes de papoula.

NOTA: codeína, dextrometorfano, folcodina, dihidrocodeína, dextropropoxifeno, etilmorfina, difenoxilato, propoxifeno e tramadol são permitidos.

\section{Agentes anabólicos}

\section{C.1. Esteróides anabolizantes androgenizantes, tais} como:

Androstenodiol, androstenodiona, bolasterona, boldenona, clostebol, danazol, dehidroclorometiltestosterona, dehidroepiandrosterona (DHEA), dihidrotestosterona, drostanolona, estanozolol, fluoximesterona, formebolona, gestrinona, mesterolona, metandienona, metandriol, metenolona, metiltestosterona, mibolerona, nandrolona, 19-norandrostenodiol, 19-norandrostenodiona, noretandrolona, oxandrolona, oximesterona, oximetolona, testosterona*, trembolona e compostos correlatos.

A relação de testosterona/epitestosterona superior a 6/1 será considerada como positiva, mas o atleta deverá ser submetido a um estudo endocrinológico, a uma análise isotópica e a testes sucessivos.

\section{C.2. Beta-2-agonistas}

Bambuterol, clenbuterol, fenoterol, formoterol, reproterol, salbutamol**, salmeterol*, terbutaline* e compostos correlatos, quando administrados por via sistêmica.

$*$ = vide estimulantes.

** $=$ em concentração superior a $1.000 \mathrm{ng} / \mathrm{ml}$ em urina será considerado como positivo para anabolizante.

\section{Diuréticos, tais como:}

Acetazolamida, ácido etacrínico, amilorida, bendroflurmetiazida, benztiazida, bumetanida, canrenona, clomerodrina, clortalidona, diclofenamida, espironolactona, furosemida, hidroclorotiazida, indapamida, manitol*, mersalil, triantereno e compostos correlatos.

* = proibido por injeção endovenosa.

\section{E. Hormônio peptídicos, substâncias miméticas e aná- logos, tais como:}

E.1. Gonadotrofina coriônica humana (HCG) - unicamente para homens:

É sabido que administração em homens de gonadotrofina coriônica humana e compostos correlatos levam a um aumento na produção endógena de esteróides androgênicos. Esta administração age de maneira similar ao hormônio luteinizante (LH), que está presente na rota fisiológica de produção de hormônios masculinos. Sendo considerada como administração exógena de testosterona, o uso desta substância, seus compostos correlatos, e seus fatores liberadores ou análogos, é proibido. 
E.2. Gonadotrofinas pituitárias e sintéticas $(\mathrm{LH})$ - unicamente para homens:

Efeito semelhante ao HCG. Estão neste grupo clomifeno, ciclofenila e tamoxifeno.

\section{E.3. Corticotrofina: (ACTH, tetracosactide)}

Tem sido usada para aumentar os níveis sanguíneos de corticóides endógenos, notoriamente para a obtenção dos efeitos euforizantes dos corticóides. A aplicação de corticotrofina é considerada equivalente ao uso de corticóide via oral, intramuscular ou intravenosa. O uso desta substância, e seus fatores liberadores ou análogos, é proibido.

E.4. Hormônio de crescimento: (HGH, somatotrofina)

O uso de hormônio de crescimento no esporte é considerado antiético e perigoso devido a várias ações colaterais, tais como reações alérgicas, efeitos diabetogênicos e acromegalia. O uso desta substância, e seus fatores liberadores ou análogos, é proibido.

\section{E.5. Fator de crescimento tipo insulina (IGF-1)}

\section{E.6. Eritropoietina (EPO):}

Este hormônio pode ser utilizado para aumentar a formação de glóbulos vermelhos, melhorando assim a capacidade de transporte de oxigênio e, por consequiência, o rendimento esportivo em modalidades de média e longa duração. O uso desta substância é proibido.

\section{E.7. Insulina:}

Permitida apenas para tratar o diabete insulino-dependente. Deverá ser feita notificação da patologia do atleta pelo endocrinologista ou médico da equipe. A presença de concentração anormal de hormônio endógeno, ou de seus marcadores para diagnóstico na urina de um competidor, se constitui em ofensa, a não ser que seja acompanhada de documentação comprovando uma condição especial, possivelmente patológica.

\section{MÉTODOS DE DOPAGEM}

\section{A. Doping sanguíneo:}

Transfusão de sangue, células vermelhas (papa de hemácias), produtos que contenham hemácias ou carreadores artificiais de oxigênio. Estes produtos podem ser obtidos do mesmo indivíduo (autotransfusão) ou de indivíduos diferentes (heterotransfusão). O uso é feito sem a justificativa legítima de tratamento médico, tal como em casos de perda sanguínea aguda ou anemia severa.

É contra-indicado pela ética do jogo e por riscos de reações alérgicas, reação hemolítica aguda, transmissão de infecção (hepatite viral e AIDS), sobrecarga de circulação e choque metabólico.

B. Administração de transportadores artificiais de oxigênio ou substitutos de plasma sanguíneo:

\section{Manipulação farmacológica, química e física da uri-} na:

É proibido o uso de substâncias e métodos que alterem, tentem alterar ou possam razoavelmente alterar a integridade e validade de amostras de urina, tal como a cateterização, a substituição de urina e/ou adulteração da mesma ou a inibição da excreção renal, através de diuréticos ou de agentes máscaras tais como o probenecide, a alteração das medidas de epitestosterona e testosterona, tais como a administração de epitestosterona* e bromantano.

O sucesso ou fracasso no uso de determinado método ou substância proibida não influi em um caso de dopagem, como também não se considera a intenção do atleta. O simples uso do método ou procedimento proibido se constitui em infração consumada.

* = uma concentração urinária de epitestosterona superior a 200 nanogramas $/ \mathrm{ml}$ será considerada como positiva de anabolizante.

\section{CLASSES DE SUBSTÂNCIAS SUJEITAS A DETERMINADAS RESTRIÇÕES:}

\section{A. Álcool:}

Seu controle pode ser solicitado por Federações Internacionais e os resultados sujeitos a sanções.

\section{B. Marijuana (canabis, maconha)}

Está formalmente proibida e a presença de seus metabólitos na urina será sancionada. Observe que podem ser encontrados estes metabólitos na urina até cerca de 5 dias depois de sua utilização. Uma concentração na urina do ácido 11-nor-delta 9-tetrahidrocanabinol-9-carboxilico (carboxi-THC) maior do que 15 nanogramas $/ \mathrm{ml}$ é proibida. Assim, eventuais fumantes passivos (que aspiram inadvertidamente a fumaça de pessoas que estão próximas) não correm o risco de serem punidos.

\section{Anestésicos locais:}

São permitidos anestésicos locais injetáveis nas seguintes condições:

- sejam usados bupivacaína, lidocaína, mepivacaína, procaína, etc., mas não cocaína. Vasoconstritores (ex.: adrenalina) podem ser associado a anestésicos locais.

- podem apenas ser usados em injeção local ou intraarticular.

- uso apenas com justificativa médica, devendo ser informado à Comissão Médica do COI por escrito, com detalhes de diagnóstico, dose e via de administração, antes da competição, ou, se administrado durante a mesma, logo após o uso da substância. 


\section{Glicocorticóides:}

Proibidos exceto para uso tópico: anal, aural, dermatológico, nasal e oftalmológico (não inclui o uso retal); terapia inalatória; e injeções locais ou intra-articulares, sendo que estes dois últimos usos devem ser notificados, principalmente no caso de atleta com asma, pelo médico da equipe desportiva, por escrito, à Comissão Médica do COI, previamente à competição.

\section{E. Betabloqueadores, tais como:}

Acebutolol, alprenolol, atenolol, betaxolol, bisoprolol, bunolol, carvedilol, labetalol, metoprolol, nadolol, oxprenolol, propranolol, sotalol e compostos correlatos. O controle pode ser solicitado por Federações Internacionais e os resultados sujeitos a sanções.

\section{ORIENTAÇÕES SOBRE PRODUTOS NATURAIS}

Este segmento visa a orientar médicos, técnicos e atletas quanto aos cuidados a serem tomados em relação a plantas, raízes, sementes e chás no que se refere a doping e seu controle, principalmente por ocasião de competições, nacionais ou internacionais.

É indispensável que o médico responsável esteja a par de todo medicamento usado pelo atleta, seja alopatia, homeopatia, fitoterapia, florais, medicina ortomolecular ou qualquer outro método administrado ou usado pelo atleta. Apenas assim poderá ser feita comunicação oficial à Comissão Médica do COI, de acordo com o regulamento.

Seria recomendado ao atleta que não comesse, bebesse, fumasse, inalasse ou injetasse (ou usasse sob alguma outra forma de administração) qualquer substância desconhecida por ele, que não tenha sido recomendada pelo médico responsável. Muitos produtos derivados de plantas nativas de várias regiões (chás, pós, sementes, preparados diversos) podem ter ação dopante ou ter reação cruzada nos exames de verificação de doping na urina, principalmente no que se refere ao efeito estimulante.

Deve haver cuidado com a manipulação de materiais desconhecidos, como pós, líquidos, resinas, pastas, etc., que podem conter substâncias proibidas, as quais, entrando em contato com o organismo, poderão repercutir em contaminação e sugerir resultado positivo para certas classes farmacológicas no controle de doping.

Por outro lado, hoje em dia existem vários tipos de suplementos alimentares, bebidas isotônicas e complexos vitamínicos que apresentam em sua formulação estimulantes e/ou esteróides anabólicos, às vezes sem discriminação na bula, que podem causar positivos em controles de dopagem.

\section{INFORMAÇÕES PARA ATLETAS, TREINADORES E MÉDICOS SOBRE O USO DE MEDICAMENTOS NO ESPORTE}

A lista de substâncias restritas se caracteriza como uma percentagem pequena do arsenal farmacológico e não impede o tratamento adequado ao atleta por razões terapêuticas justificáveis.

A relação das substâncias permitidas aqui propostas, para o uso no Brasil, tem apenas o sentido de orientação, sendo mencionados apenas alguns dos produtos mais utilizados em nosso meio. Está claro que a prescrição do fármaco fica rigorosamente a critério do médico e que esta lista não possui um caráter restritivo.

Devem ser tomados cuidados especiais quanto à prescrição de remédios para dor, resfriados, cefaléias e problemas nasais e brônquicos. Preparações que só contenham antibiótico ou anti-histamínico são permitidas, mas devese estar atento para as preparações combinadas que contenham efedrina e aminas simpaticomiméticas.

Observe-se que, sob o mesmo nome comercial, pode haver preparações combinadas, como vitaminas, que tenham, em sua composição, estimulantes psicomotores e anabólicos esteróides.

Deve-se, também, lembrar que as regras da Federação Internacional de Pentatlo não permitem certas substâncias tais como tranqüilizantes, que não são proibidas nos demais esportes.

Observação: toda a medicação citada aparecerá sob o seu nome comercial e se apresentará dentro das especificações adotadas pelo COI.

\section{LISTA DE FÁRMACOS PERMITIDOS}

\section{Antiácidos}

Aclorisan, Alca-luftal, Alrac, Andursil, Asilone, Bisuisan, Digastril, Estomagel, Gastrogel, Gastrol, Gastromag Gel, Gelusil M, Hidroxogel, Kolantyl, Leite de Magnésia, Maalox Plus, Magnésia Bisurada, Mylanta Plus, Pepsamar, Pepsogel, Siligel, Siludrox, Simecoplus, Sonrisal e outros de composição semelhante.

\section{Antidiarréicos}

Colestase, Diarresec, Enterobion, Floratil, Florax, Furazolin, Imosec, Kaomagma, Kaopectate, Lomotil, Parenterin e outros de composição semelhante. Observe que não devem ser utilizadas preparações que contenham ópio (por ex.: elixir paregórico).

\section{Antiasmáticos}

Aerolin, Bricanyl. 
Obs.: Estes medicamentos estão indicados apenas sob forma de aerossóis ou preparações para inalação.

\section{Antialérgicos}

Agasten, Calamina, Cilergil, Fenergan, Hismanal, Intal, Periatin, Polaramine, Prometazina, Teldane e outros de composição semelhante.

\section{Antinauseantes-antieméticos}

6-Copena, Diagrin, Dramin, Emetic, Estac, Eucil, Metoclopramida, Motilium, Normopride enzimático, Plamet, Plasil, Vogalene, Vomix, Vontrol e outros de composição semelhante.

\section{Antiulcerosos}

Antak, Cimetidina, Climatidine, Gastrodine, Label, Logat, Neocidine, Ranidin, Ranitidina, Tagamet, Ulcedine, Ulcenon, Ulcoren, Zadine e outros de composição semelhante.

\section{Analgésicos, antipiréticos e antiespasmódicos}

AAS, AAS Infantil, Acetaminofen, Acetaminofen 500, Ácido acetilsalicílico 500mg, Ácido acetilsalicílico infantil, Aspiçucar, Aspirina, Aspirina infantil, Baralgin, Buscopan, Dipirona, Doran, Dôrico, Endosalil, Novalgina, Pacemol, Ponstan, Ronal, Tylenol, Tylex e outros de composição semelhante.

\section{Antiinflamatórios}

Actiprofen, Advil, Aflogen, Algi-danilon, Algi-flamanil, Alginflay, Algi-peralgin, Algizolin, Analtrix, Anartrit, Artren, Artril, Artrinid, Artrosi, Benervan, Benotrin, Benzitrat, Biofenac, Brexin, Butazil, Butazolidina, Butazona, Cataflam, Cataflam-D, Cataren, Cetoprofeno, Cicladol, Celebra, Ciclinalgin, Clofenak, Danilon, Deflogen, Deltaflam, Deltaflogin, Deltaren, Diclofenaco sódico, Diclofenaco potássico, Diclotaren, Doretrin, Dorgen, Doriflan, Eudoxicam, Eridamin, Flanax, Fenaflan, Febupen, Feldene, Feldox, Felnam, Fenaflan sódico, Fenaren, Fenburil, Fenilbutazona sódica, Fisioren, Flotac, Indocid, Inflamene, Motrin, Naprosyn, Nisulid, Piroxifen, Piroxiflam, Proflam, Scaflam, Sintalgin, Tilatil, Vioxx, Voltaren e outros de composição semelhante.

\section{Antigripais}

Analgex C, Aspi-C, Cebion, Cortegripan, Melhoral C, Redoxon.

Obs.: A maioria dos antigripais contém efedrina elou cafeína, substâncias proibidas.

\section{Contraceptivos}

Anacyclin, Anfertil, Biofim, Evanor, Gynera, Micronor, Microvlar, Minulet, Neovlar, Nordette, Normamor, Trinordiol e outros de composição semelhante.

\section{Descongestionantes nasais}

Otrivina, Rinosoro, Sorine.

\section{Expectorantes e antitussígenos}

Alergogel, Alergotox expectorante, Atossion, Benadryl expectorante, Benadryl, Besedan, Bisolvon, Bisolvon ampicilina, Clistin expectorante, Fluimucil 10 a 20\%, Glicodin, GlyconIodepol, Iodetal, Iodeto de Potássio Líquido, Pulmonix, Rinofluimucil, Silomat, Subitan, Transpulmin, Xarope de Iodeto de Potássio composto, Xarope Valda e outros de composição semelhante.

\section{Antifúngico}

Ancotil, Canesten, Cetoconazol, Daktarin, Flagyl, Flagyl-nistatina, Fluconazol, Fulcin, Fungizon, Micostatin, Nistatina, Nizoral, Sporostatin e outros de composição semelhante.

\section{Anti-hemorroidários}

Claudemor, Glyvenol, Hemorroidex, Nestosyl, Novaboin, Novarrurita, Venalot H-creme, Xyloproct e outros de composição semelhante.

\section{Hipnóticos}

Benzodiazepínicos: Dalmadorm, Nitrazepan, Nitrazepol, Rohypnol, Sonebon, e outros de composição semelhante.

Barbitúricos: Fenergan, Prometazina e outros de composição semelhante.

Sedativos: Ansitec, Calmociteno, Diazepam, Dienpax, Frisium, Kiatrium, Lexotan, Lorax, Psicosedin, Somalium, Tensil, Tranxilene, Valium e outros de composição semelhante.

Obs.: A Federação Internacional de Pentatlo Moderno não permite o uso de sedativos nas provas da modalidade de tiro deste esporte.

\section{Antidiabéticos}

Hipoglicemiantes orais: Daonil, Diabinese, Diamicron, Glibenclamida, Minidiab e outros de composição semelhante.

\section{Relaxantes musculares periféricos}

Coltrax, Mioflex, Sirdalud.

Observe que muitos relaxantes musculares periféricos contêm cafeína, que é uma substância proibida, da classe dos estimulantes. 


\section{Tópicos dermatológicos}

Podem ser usados todos os produtos existentes no mercado, desde que seja respeitada sua indicação e que, preferentemente, sejam usados por prescrição médica.

\section{Preparações vaginais}

Flagyl, Ginedak, Ginodex, Gyno-daktarin, Micogyn, Nistatina, Talsutin e outros de composição semelhante.

\section{Preparações oftálmicas}

Anestalcon colírio, Cloranfenicol, Colírio cicloplégico, Dexafenicol, Flumex 0,10\% e 0,25\%, Fluoresceína, Isopto Carpine, Lacrima, Maxidex, Maxitrol, Midriacyl 1\%, Minidex, Opti-tears, Pilocarpina 1\%, 2\% e 4\%, Timolol 0,25\% e $0,50 \%$, Timoptol e outros de composição semelhante.

\section{Antibióticos}

Amicacina, Amoxicilina Amoxifar, Amoxil, Ampicil, Ampicilina, Ampicron, Ampitotal, Amplacilina, Amplitor, Assepium Balsâmico, Bacfar, Bacgen, Bacterion, Bactrim, Bactrim F, Balsiprim, Benectrin, Benzetacil, Binotal, Bipencil, Cápsulas de Tetraciclina, Carbenicilina, Ceclor, Cefalex, Cefalexina, Cefalotina, Cefamezin, Cefaporex, Cibramox, Clindamicina, Cloranfenicol, Cloridrato de Tetraciclina, Dalacin-C, Despacilina, Diastin, Dicloxacilina, Dientrin, Duoctrin, Eritrex, Eritrofar, Espectrin, Garami-

\section{REFERÊNCIAS}

1. DEF 99/2000. Dicionário de Especialidades Farmacêuticas. Jornal Brasileiro de Medicina. $28^{\underline{a}}$ ed. Rio de Janeiro: Editora de Publicações Científicas Ltda., 1999.

2. De Rose EH, Nóbrega ACL. Drogas lícitas e ilícitas. In: Ghorayeb N, Barros Neto TL, editores. O exercício - preparação fisiológica, avaliação médica e aspectos especiais e preventivos. São Paulo: Atheneu, 1999: 395-405.

3. Dugal R. Carta a Jane Gatehouse. Lista de medicações permitidas. Lausanne, 15-16 ab. 1989:18p. cina Injetável, Gentamicina, Glitisol, Hiconcil, Ilosone, Imuneprim, Infectrin, Kefazol, Keflex, Lincomicina, Longacilin, Mefoxin, Megapen, Netromicina, Novamin, Novocilin, Oracilin, Oxacilina, Panglobe, Penicilina G Potássica Cristalizada, Pantomicina, Pen-ve-oral, Penvicilin, Septiolan, Sintomicetina Staficilin-N, Terramicina, Tetraciclina, Tetrex, Tobramina, Totapen, Trimexazol Trozyman, Vancomicina, Vibramicina e outros de composição semelhante.

\section{Anticonvulsivantes}

Depakene, Diempax (oral e injetável), Epelin, Fenobarbital, Gardenal (oral e injetável), Hidantal, Primidona, Rivotril, Tegretol, Valium, Valpakine e outros de composição semelhante.

\section{Laxativos}

Agarol, Agiolax, Dulcolax, Fitolax, Fleet enema, Frutalax, Guttalax, Humectol D, Lacto-purga, Metamucil, Minilax, Óleo mineral, Purgoleite, Supositório de glicerina, Tamarine e outros de composição semelhante.

\section{Vitaminas}

Podem ser usadas todas aquelas que não apresentarem em sua formulação nenhum tipo de substância proibidas, tais como estimulantes ou anabólicos e seus precursores.

4. Goodman and Gilman's. The pharmacological basis of therapeutics. $9^{\text {th }}$ ed. New York: McGraw-Hill, 1996.

5. International Olympic Committee. List of doping classes and methods (atualizações anuais).

6. Lima DR. Manual de farmacologia clínica e terapêutica. Rio de Janeiro: Medsi, 1984.

7. P.R. Vade-mécum 1997-1998 (edição de bolso). Manual de medicamentos. São Paulo: Soriak, 1997.

8. Voy RO. Clinical aspects of the doping classes. In: The encyclopedia of sports medicine. Blackwell Scientific Publications, 1988. 